\title{
Development and Validation of HPTLC Method for Estimation of Propranolol Hydrochloride and Flunarizine Dihydrochloride in Combined Dosage Form
}

\author{
Palak Patel and Kashyap K. Bhatt \\ Indukaka Ipcowala College of Pharmacy, Beyond GIDC, P.O. Box NO. 53, Gujarat Vitthal Udyognagar 388 121, India \\ Correspondence should be addressed to Palak Patel, palakpatel07@gmail.com
}

Received 5 March 2012; Accepted 29 April 2012

Academic Editors: A. M. Haji Shabani and B. Rittich

Copyright $\odot 2012$ P. Patel and K. K. Bhatt. This is an open access article distributed under the Creative Commons Attribution License, which permits unrestricted use, distribution, and reproduction in any medium, provided the original work is properly cited.

\begin{abstract}
A simple, sensitive, and precise high-performance thin layer chromatographic method has been developed for the estimation of propranolol hydrochloride and Flunarizine dihydrochloride in combined dosage form. The method employed HPTLC aluminum plates precoated with silica gel $60 \mathrm{~F}$ as the stationary phase while the solvent system was toluene:methanol: ethyl acetate: acetic acid $(7: 1.5: 1.5: 0.1 \mathrm{v} / \mathrm{v} / \mathrm{v} / \mathrm{v})$. The Rf value was observed to be $0.07 \pm 0.02$ and $0.67 \pm 0.02$ for propranolol hydrochloride and flunarizine dihydrochloride. The densitometric analysis was carried out in absorbance mode at $240 \mathrm{~nm}$. The method was linear in the range of 400-2400 ng/band for propranolol hydrochloride and 50-300 ng/band for flunarizine dihydrochloride. The method was validated with respected accuracy, precision and specificity. The limit of detection for Propranolol hydrochloride and flunarizine dihydrochloride were found to be 118.4 and $13.75 \mathrm{ng} / \mathrm{spot}$, respectively. The limit of quantification for propranolol hydrochloride and flunarizine dihydrochloride was found to be 355.2 and $45.4 \mathrm{ng} / \mathrm{band}$, respectively. The method was successfully applied to the estimation of propranolol hydrochloride and flunarizine dihydrochloride in combined dosage form.
\end{abstract}

\section{Introduction}

Propranolol hydrochloride (PRO) is chemically, (RS)-2(4-(2-methylpropyl) phenyl) 2-Propanol, 1-[(1-methylethyl) amino]-3-(1-naphthalenyloxy), hydrochloride. The empirical formula of $\mathrm{PRO}$ is $\mathrm{C}_{16} \mathrm{H}_{21} \mathrm{NO}_{2} \cdot \mathrm{HCl}$ and has a molecular weight of $295.80 \mathrm{~g} / \mathrm{mole}$ (Figure 1). It is antihypertensive agent used in hypertension [1]. Flunarizine dihydrochloride (FLU) is chemically 1-(bis(4-fluorophenyl)methyl)-4-(3phenyl-2 propenyl)piperazine $[2,3]$. It has an empirical formula $\mathrm{C}_{26} \mathrm{H}_{26} \mathrm{~F}_{2} \mathrm{~N}_{2}$ and a molecular weight of $404.495 \mathrm{~g} / \mathrm{mole}$ (Figure 2). It is a calcium-blocking agent [1]. The combination dosage form of propranolol hydrochloride and Flunarizine dihydrochloride is available in the market, and it is indicated in the treatment of hypertension.

Propranolol hydrochloride is official in Indian Pharmacopoeia and British Pharmacopoeia. A literature survey regarding quantitative analysis of these drugs propranolol hydrochloride and flunarizine dihydrochloride revealed that attempts have been made to develop analytical methods for the estimation of alone and in combination with other drugs by liquid chromatographic (LC) [4-8], fluorometry [9], and spectrophotometric methods [10]. Flunarizine dihydrocholride is official in United State Pharmacopoeia. Literature survey revealed that liquid chromatographic (LC) [11-15] and spectrophotometric methods $[16,17]$ and HPLC(1519) have been reported for the estimation of flunarizine dihydrochloride.

There is no method reported for the estimation of PRO and FLU in combined dosage form. Present study involves development and validation of HPTLC method for the estimation of PRO and FLU in combined dosage form.

\section{Experimental}

2.1. Apparatus. The samples were applied in the form of a bands of width $6 \mathrm{~mm}$ with a Camag $10 \mu \mathrm{L}$ sample syringe 
<smiles>CC(CCl)NCC(O)COc1cccc2ccccc12</smiles>

FIGURE 1: Structure of Propranolol hydrochloride.

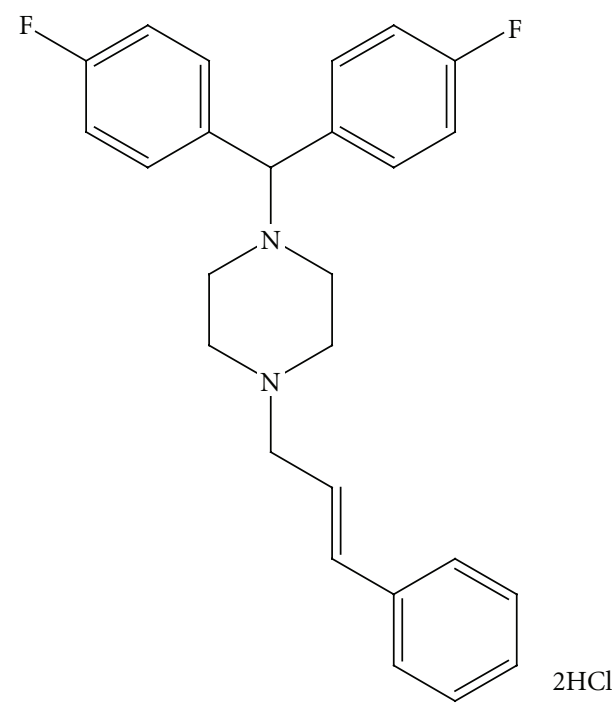

FIgURE 2: Structure of flunarizine dihydrochloride.

(Hamilton, Switzerland) using Camag Linomat 5 (Switzerland) sample applicator on precoated silica gel aluminum plate $60 \mathrm{~F} 254(10 \mathrm{~cm} \times 10 \mathrm{~cm}$ with $0.2 \mathrm{~mm}$ thickness, E. Merck, Germany). Camag TLC scanner was used for the densitometric scanning of the developed chromatogram. All the drugs and chemicals were weighed on Shimadzu electronic balance (AX 200, Shimadzu Corp., Japan).

2.2. Reagents and Materials. Analytically pure PRO and FLU were obtained as gift samples from CADILA Pharmaceutical, Ahmedabad. Analytical grade methanol, ethyl acetate, toluene, and oxalic acid were obtained from E. Merck Ltd., Mumbai, India. Tablet formulation (BETACAP, Sun pharma, baroda, India) containing labeled amount of $50 \mathrm{mg}$ of Propranolol hydrochloride and $4 \mathrm{mg}$ of Flunarizine dihydrocholride was used for the study.

2.3. Chromatographic Conditions. Plates were developed using a mobile phase consisting of toluene:methanol: ethyl acetate: acetic acid ( $7: 1.5: 1.5: 0.1 \mathrm{v} / \mathrm{v} / \mathrm{v} / \mathrm{v})$. Linear ascending development was carried out in a twin-trough glass chamber equilibrated with the mobile phase vapors for $30 \mathrm{~min}$ at $25^{\circ} \mathrm{C} \pm 2{ }^{\circ} \mathrm{C}$. Ten milliliters of the mobile phase $(5 \mathrm{~mL}$ in the trough containing the plate and $5 \mathrm{~mL}$ in the other trough) was used for each development and was allowed to migrate a distance of $80 \mathrm{~mm}$. After development, the HPTLC plates were dried completely.
2.4. Preparation of Standard Stock Solutions. Standards and formulation samples of PRO and FLU were applied on the HPTLC plates in the form of narrow bands of $6 \mathrm{~mm}$ length, $10 \mathrm{~mm}$ from the bottom and left edge, and with $9 \mathrm{~mm}$ distance between two bands. Samples were applied under a continuous drying stream of nitrogen gas.

2.5. Mobile Phase and Development. Plates were developed using a mobile phase consisting of toluene:methanol: ethyl acetate: acetic acid ( $7: 1.5: 1.5: 0.1 \mathrm{v} / \mathrm{v} / \mathrm{v} / \mathrm{v})$. Linear ascending development was carried out in a twin-trough glass chamber equilibrated with the mobile phase vapors for $30 \mathrm{~min}$ at $25^{\circ} \mathrm{C} \pm 2{ }^{\circ} \mathrm{C}$. Ten milliliters of the mobile phase $(5 \mathrm{~mL}$ in the trough containing the plate and $5 \mathrm{~mL}$ in the other trough) was used for each development and was allowed to migrate a distance of $80 \mathrm{~mm}$. After development, the HPTLC plates were dried completely.

2.6. Densitometric Analysis. Densitometric scanning was performed in the absorbance mode under control by winCATS planar chromatography software. The source of radiation was the deuterium lamp, and bands were scanned at $240 \mathrm{~nm}$. The slit dimensions were $5 \mathrm{~mm}$ length and $0.45 \mathrm{~mm}$ width, with a scanning rate of $20 \mathrm{~mm} / \mathrm{s}$. Concentrations of the compound chromatographed were determined from the intensity of diffusely reflected light and evaluated as peak areas against concentrations using a linear regression equation.

2.6.1. Preparation of Standard Stock Solution. PRO and FLU were weighed ( $25 \mathrm{mg}$ each), and transferred to two separate $25 \mathrm{~mL}$ volumetric flasks, and dissolved in few $\mathrm{mL}$ of mobile phase. Volumes were made up to the mark with mobile phase to yield a solution containing $1000 \mu \mathrm{g} / \mathrm{mL}$ of PRO and FLU, respectively. Aliquot from the stock solutions of PRO and FLU were appropriately diluted with mobile phase to obtain working standard of $100 \mu \mathrm{g} / \mathrm{mL}$ of PRO and FLU, respectively.

2.7. Method Validation. Validation of the developed HPTLC method was carried out according to International Conference on Harmonisation (ICH) guidelines Q2 (R1) for specificity, sensitivity, accuracy, precision, repeatability, and robustness [12].

2.7.1. Linearity of Calibration Curves. Linearity of the method was evaluated by constructing calibration curves at six concentration levels over a range of 400-2400 ng/band and $50-300 \mathrm{ng} / \mathrm{band}$ of IBU and FAM, respectively. The calibration curves were developed by plotting peak area versus concentration $(n=6)$ with the help of the winCATS software.

2.7.2. Accuracy. The accuracy of the method was determined by calculating recoveries of PRO and FLU by method of standard additions. Known amount of PRO (0, 200, 400, and $600 \mathrm{ng} / \mathrm{band})$ and FLU (0, 25, 50, and $75 \mathrm{ng} / \mathrm{band})$ were added to a prequantified sample, and the amounts of PRO 
and FLU were estimated by measuring the peak area and by fitting these values to the straight-line equation of calibration curve.

2.7.3. Precision. Precision was evaluated in terms of intraday and interday precisions. Intraday precision was determined by analyzing sample solutions of $\mathrm{PRO}(400,1600$, and $2400 \mathrm{ng} / \mathrm{band})$ and FLU (50, 200, and $300 \mathrm{ng} / \mathrm{band})$ at three levels covering low, medium, and high concentrations of the calibration curve three times on the same day $(n=$ $3)$. Interday precision was determined by analyzing sample solutions of $\mathrm{PRO}(400,1600$, and $2400 \mathrm{ng} / \mathrm{band})$ and FLU(50, 200 , and $300 \mathrm{ng} / \mathrm{band}$ ) at three levels covering low, medium, and high concentrations over a period of 3 days $(n=3)$. The peak areas obtained were used to calculate mean and RSD values.

Repeatability of measurement of peak area was determined by analyzing PRO and FLU samples (1600 and $200 \mathrm{ng} / \mathrm{band}$ ) seven times without changing the position of plate.

2.7.4. Specificity. The specificity of the method was ascertained by analyzing PRO and FLU in presence of excipients commonly used for tablet formulations. The bands of PRO and FLU were confirmed by comparing $\mathrm{Rf}$ values and respective spectra of sample with those of standards. The peak purity of PRO and FLU was assured by comparing the spectra at three different levels, that is, peak start, peak apex, and peak end positions.

2.7.5. Sensitivity. The limit of detection (LOD) is defined as the lowest concentration of an analyte that can reliably be differentiated from background levels. Limit of quantification (LOQ) of an individual analytical procedure is the lowest amount of analyte that can be quantitatively determined with suitable precision and accuracy. LOD and LOQ were calculated using following equation as per ICH guidelines:

$\mathrm{LOD}=3.3 \times \sigma / \mathrm{S} ; \mathrm{LOQ}=10 \times \sigma / \mathrm{S}$, where, is the standard deviation of $y$-intercepts of regression lines and $S$ is the slope of the calibration curve.

2.7.6. Robustness. Small changes in the chamber saturation time and solvent migration distance were introduced, and the effects on the results were examined. Robustness of the method was determined in triplicate at a concentration level of $1600 \mathrm{ng} / \mathrm{band}$ and $200 \mathrm{ng} / \mathrm{band}$ of PRO and FLU, respectively. The mean and RSD of peak areas were calculated.

2.7.7. Solution Stability. Stability of sample solutions were studied at $25 \pm 2{ }^{\circ} \mathrm{C}$ for $24 \mathrm{~h}$.

2.8. Analysis of Marketed Formulations. Twenty tablets were weighed accurately and finely powdered. Tablet powder equivalent to $50 \mathrm{mg}$ PRO and $4 \mathrm{mg}$ of FLU was taken in $100 \mathrm{~mL}$ volumetric flask. Methanol $(50 \mathrm{~mL})$ was added to this flask, and the flask was sonicated for 15 minutes. The solution was filtered using Whatman filter paper No.1, and volume was made up to the mark with the mobile phase.
Appropriate volume of the aliquot was transferred to a $10 \mathrm{~mL}$ volumetric flask, and the volume was made up to the mark with the mobile phase to obtain a solution containing $400 \mathrm{ng} / \mathrm{band}$ of PRO and $50 \mathrm{ng} / \mathrm{band}$ of FLU were applied to HPTLC plates and analyzed for PRO and FLU content using the proposed method as described earlier. The possibility of interference from other components of the tablet formulation in the analysis was studied. From the developed chromatogram spot area and $\mathrm{Rf}$ values were determined.

\section{Results and Discussion}

3.1. Optimization of the Mobile Phase. To develop the HPTLC method of analysis of PRO and FLU for routine analysis, selection of the mobile phase was carried out on the basis of polarity. A mobile phase that would give a dense and compact band with an appropriate Rf value for PRO and FLU was desired. Various mobile phases such as methanol, hexane, methanol-ethyl acetate, hexane-ethyl acetate, methanoltoluene, methanol-n-butanol and methanol-ethyl acetatetoluene were evaluated in different proportions. A mobile phase consisting of toluene: methanol: ethyl acetate: acetic acid $(7: 1.5: 1.5: 0.1, \mathrm{v} / \mathrm{v} / \mathrm{v} / \mathrm{v})$ gave good separation of PRO and FLU from its matrix. It was also observed that chamber saturation time and solvent migration distance were crucial in the chromatographic separation, as chamber saturation time of less than $30 \mathrm{~min}$ and solvent migration distances greater than $80 \mathrm{~mm}$ resulted in diffusion of the analyte band. Therefore, toluene: methanol : ethyl acetate: acetic acid $(7: 1.5: 1.5: 0.5 \mathrm{v} / \mathrm{v} / \mathrm{v} / \mathrm{v})$ mobile phase with a chamber saturation time of $30 \mathrm{~min}$ at $25^{\circ} \mathrm{C}$ and solvent migration distance of $80 \mathrm{~mm}$ was used. These chromatographic conditions produced a well-defined compact band of PRO and FLU with optimum migration at Rf $0.07 \pm 0.02$ and $0.67 \pm 0.02$, respectively. (Figures 3 and 4 ).

\subsection{Method Validation}

3.2.1. Linearity and Calibration Curves. Linearity of an analytical method is its ability, within a given range, to obtain test results that are directly, or through a mathematical transformation, proportional to the concentration of the analyte. The method was found to be linear in a concentration range of 400-2400 ng/band and 50-300 ng/band of PRO and FLU, respectively, $(n=6)$ with respect to peak area. Figure 5 displays a three dimensional overlay of HPTLC densitograms of the calibration bands of PRO and FLU at $240 \mathrm{~nm}$. The regression data shown in Table 1 reveal a good linear relationship over the concentration range studied, demonstrating the suitability of the method for analysis.

3.2.2. Accuracy. Accuracy of an analytical method is the closeness of test results to the true value. It was determined by the application of analytical procedure to recovery studies, where a known amount of standard is spiked into preanalyzed samples solutions. Results of the accuracy studies from excipient matrix are shown in Table 2; recovery values 


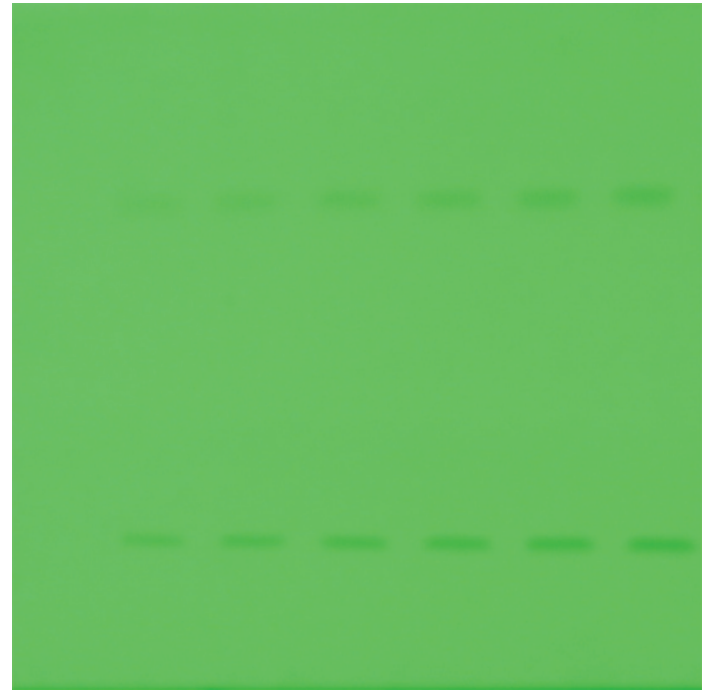

FIgURE 3: Densitogram of PRO, and FLU using mobile phase toluene:methanol: ethyl acetate: oxalic acid $(7: 1.5: 1.5: 0.1$, $\mathrm{v} / \mathrm{v} / \mathrm{v} / \mathrm{v})$.

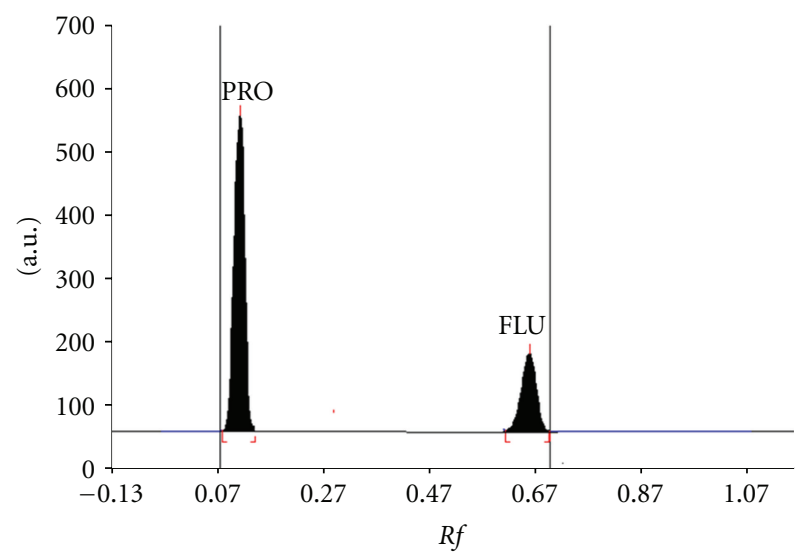

FIGURE 4: Chromatogram of PROand FLU (400 and $50 \mathrm{ng} / \mathrm{band}$ ) using mobile phase toluene:methanol: ethyl acetate: oxalic acid $(7: 1.5: 1.5: 0.1, \mathrm{v} / \mathrm{v} / \mathrm{v} / \mathrm{v})$.

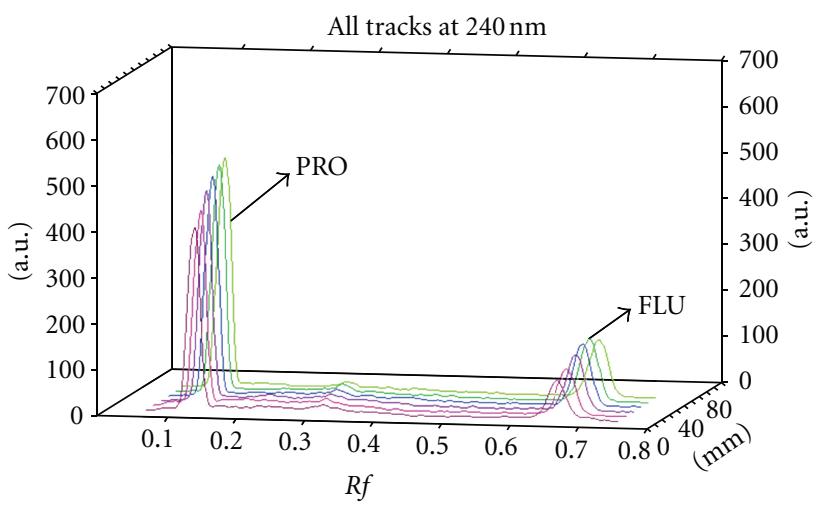

FIgURE 5: Three dimensional overlay of HPTLC densitograms of calibration bands of PRO and FLU.
TABLE 1: Regression analysis of calibration curve.

\begin{tabular}{lcc}
\hline Parameter & PRO & FLU \\
\hline Linearity $(\mu \mathrm{g} / \mathrm{mL})$ & $400-2400$ & $50-300$ \\
Correlation coefficient $(r)$ & 0.974 & 0.989 \\
Slope of regression & 0.94 & 4.013 \\
Standard deviation of slope & 0.060 & 0.2372 \\
Intercept of regression & 5356.4 & 1373.4 \\
Standard deviation of intercept & 79.128 & 55.456 \\
\hline
\end{tabular}

TABLE 2: Summary of validation parameters.

\begin{tabular}{lcc}
\hline Parameters & PRO & FLU \\
\hline Rf & $0.07 \pm 0.02$ & $0.67 \pm 0.02$ \\
Detection limit $(\mu \mathrm{g} / \mathrm{ml})$ & 118.4 & 13.75 \\
Quantitation limit $(\mu \mathrm{g} / \mathrm{ml})$ & 355.2 & 45.4 \\
Accuracy $(\%)$ & $99.71-100.92 \%$ & $98.8-101.27$ \\
Precision $\left(\mathrm{RSD}^{\mathrm{a}}, \%\right)$ & & \\
$\quad$ Intraday precision $(n=3)$ & $1.06-1.33$ & $1.28-1.48$ \\
$\quad$ Interday precision $(n=3)$ & $0.237-0.65$ & $0.66-0.88$ \\
Instrument precision $\left(\mathrm{RSD}^{\mathrm{a}}\right)$ & 0.09 & 0.24 \\
\hline
\end{tabular}

aRSD is relative standard deviation and " $n$ " is number of determinations.

demonstrated the accuracy of the method in the desired range.

3.2.3. Precision. The precision of an analytical method expresses the degree of scatter among a series of measurements obtained from multiple sampling of the same homogeneous sample under prescribed conditions. Intraday precision refers to the use of an analytical procedure within a laboratory over a short period of time by the same operator with the same equipment, whereas interday precision involves estimation of variations in analysis when a method is used within a laboratory on different days. The results obtained are shown in Table 2. In all instances, RSD values were less than $2 \%$, confirming the precision of the method. Repeatability of the scanning device was studied by applying and analyzing PRO and FLU sample (1600 and $200 \mathrm{ng} /$ band) seven times. RSD was less than $2 \%$ (Table 2), which was well below the instrumental specifications.

3.2.4. Limit of Detection and Limit of Quantification. Under the experimental conditions used, the lowest amount of drug that could be detected (LOD) for PRO and FLU was found to be 118.4 and $13.75 \mathrm{ng} / \mathrm{band}$, respectively. The limit of quantification (LOQ) for PRO and FLU was found to be 355.2 and $45.4 \mathrm{ng} /$ band, respectively, with an RSD $<2 \%$.

3.2.5. Robustness. The low values of RSD (Table 3 ) obtained after introducing small, deliberate changes in parameters of the developed HPTLC method confirmed its robustness.

3.2.6. Specificity. Specificity is the ability of an analytical method to determine the analyte unequivocally in the presence of sample matrix. Specificity of the method for PRO 
TABLE 3: Robustness studies.

\begin{tabular}{|c|c|c|c|}
\hline \multirow{2}{*}{ Method parameter/condition } & \multirow{2}{*}{ Deliberate changes } & \multicolumn{2}{|c|}{$\%$ RSD of peak area $(n=3)$} \\
\hline & & PRO & FLU \\
\hline \multirow{2}{*}{ Chamber saturation time ${ }^{(a)}$} & $20 \mathrm{~min}$ & 0.93 & 0.67 \\
\hline & $40 \mathrm{~min}$ & 1.13 & 0.98 \\
\hline \multirow{2}{*}{ Development distance from spot application ${ }^{(b)}$} & $75 \mathrm{~mm}$ & 0.39 & 0.86 \\
\hline & $85 \mathrm{~mm}$ & 0.98 & 1.16 \\
\hline
\end{tabular}

(a) $\pm 20 \%$ change in set time.

(b) $\pm 10 \%$ change in set distance.

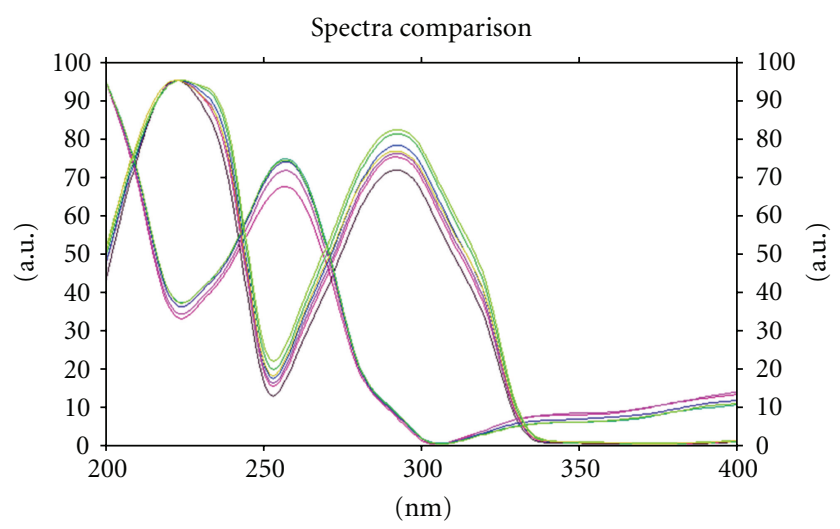

FIgURE 6: Spectra comparison of PRO and FLU.

TABLE 4: Peak purity correlation results of PRO and FLU in given formulations.

\begin{tabular}{lc}
\hline Sample & Peak purity \\
\hline PRO & 0.998 \\
PRO formulation & 0.995 \\
FLU & 0.997 \\
FLU formulation & 0.994 \\
\hline
\end{tabular}

TABLE 5: Analysis of marketed formulation.

\begin{tabular}{lccccc}
\hline \multirow{2}{*}{ Formulations Labelled amount (mg) } & \multicolumn{2}{c}{ \% Recovery } \\
& PRO & FLU & PRO & FLU \\
\hline A & 40 & 5 & $100.01 \pm 0.72$ & $99.25 \pm 0.37$ \\
\hline
\end{tabular}

${ }^{\mathrm{b}}$ Mean value \pm standard deviation of three determinations; tablet formulation A is BETACAP(Sun Pharma, India) containing labeled amount of $40 \mathrm{mg}$ of PRO and $5 \mathrm{mg}$ of FLU.

and FLU was proved from the spectral scan (Figure 6), and peak purity correlation (r) results (Table 4) for PRO and FLU in tablet formulations indicate that there is no coeluting peak with PRO and FLU, so there is no interference from any excipients present in tablet formulation.

3.2.7. Analysis of Marketed Formulation. Marketed formulation was analyzed using proposed method which gave percentage recovery for PRO and FLU were $100.07 \pm 0.72$ and $99.25 \pm 0.37$, respectively (Table 5). A single band at Rf $0.07 \pm$ 0.02 and $0.67 \pm 0.02$ was observed in the chromatogram for PRO and FLU, and no interference from the excipients present in the marketed tablet formulation was observed.

\section{Conclusions}

A simple accurate and precise HPTLC method has been developed for the identification and quantification of RPO and FLU. The method was successfully validated in accordance with ICH guidelines. It can be conveniently used for routine QC analysis of PRO and FLU as a bulk drug and in marketed tablets without any interference from excipients.

\section{Acknowledgments}

The authors are thankful to CADILA pharmaceutical, Ahmedabad, India for providing gift sample of PRO and FLU, respectively. They are very thankful to Principal, Indukaka Ipcowala College of Pharmacy, New Vallabh Vidyanagar for providing necessary facilities to carry out research work.

\section{References}

[1] British Pharmacopoeia, London, UK, General Medical Council, vol. 1, 2004.

[2] USP-NF, United States Pharmacopoeia, Convention, 2004, Asian edition.

[3] Indian Pharmacopoeia, Government of India, Ministry of Health and Family Welfare, vol. 3, The Controller of Publication, Delhi, India, 2007.

[4] M. W. Lo, B. Silber, and S. Riegelman, "An automated HPLC method for the assay of propranolol and its basic metabolites in plasma and urine," Journal of Chromatographic Science, vol. 20, no. 3, pp. 126-131, 1982.

[5] E. C. Kwong and D. D. Shen, "Versatile isocratic highperformance liquid chromatographic assay for propranolol and its basic, neutral and acidic metabolites in biological fluids," Journal of Chromatography, vol. 414, no. 2, pp. 365379, 1987.

[6] S. Laganiere, E. Kwong, and D. D. Shen, "Stereoselective highperformance liquid chromatographic assay for propranolol enantiomers in serum," Journal of Chromatography, vol. 488, no. 2, pp. 407-416, 1989.

[7] E. C. Kwong and D. D. Shen, "Versatile isocratic highperformanceliquid chromatographic assay for propranolol and its basic, neutral and acidic metabolites in biological fluids," Journal of Chromatography, vol. 414, no. 2, pp. 365379, 1987. 
[8] S. Laganiere, E. Kwong, and D. D. Shen, "Stereoselective highperformance liquid chromatographic assay for propranolol enantiomers in serum," Journal of Chromatography, vol. 488, no. 2, pp. 407-416, 1989.

[9] J. F. Pritchard, D. W. Schneck, W. J. Racz, and A. H. Hayes Jr., "The contribution of propranolol metabolites to the fluorometric assay of propranolol in human plasma," Clinical Biochemistry, vol. 11, no. 3, pp. 121-125, 1978.

[10] N. M. Sanghavi and N. G. Jivani, "Estimation of propranolol hydrochloride," Talanta, vol. 27, no. 7, pp. 591-592, 1980.

[11] C. D. Torchin, I. M. Kapetanovic, W. D. Yonekawa, and H. J. Kupferberg, "High-performance liquid chromatographic assay of flunarizine, (E)-1-[bis(4-fluorophenyl)methyl]-4(3-phenyl-2-propenyl)piperazine, in plasma of epileptic patients," Journal of Chromatography, vol. 426, no. 2, pp. 444448, 1988.

[12] M. Nieder and H. Jaeger, "High-performance liquid chromatographic assay of flunarizine in plasma and its application to biopharmaceutic investigations," Journal of Chromatography, vol. 380, no. 2, pp. 443-449, 1986.

[13] A. A. M. Wahbi, A. F. M. El-Walily, E. M. Hassan, F. G. Saliman, and A. El-Gendi, "Liquid chromatographic determination of flunarizine dihydrochloride in the presence of its degradation product," Journal of Pharmaceutical and Biomedical Analysis, vol. 13, no. 6, pp. 777-784, 1995.

[14] M. R. Fuh and C. J. Hsieh, "Determination of flunarizine in rat brain by liquid chromatography-electrospray mass spectrometry," Journal of Chromatography B, vol. 736, no. 12, pp. 167-173, 1999.

[15] H. Tsing, "Determination of flunarizine hydrochloride in human plasma by HPLC and its pharmacokinetics," Chinese Journal of Pharmaceutical Analysis.

[16] A. F. M. El Walily, A. El Gindy, and A. A. M. Wahbi, "Spectrophotometric determination of flunarizine dihydrochloride through the formation of charge-transfer complex with iodine," Journal of Pharmaceutical and Biomedical Analysis, vol. 13, no. 1, pp. 53-58, 1995.

[17] K. Busaranon, W. Suntornsuk, and L. Suntornsuk, "Comparison of UV spectrophotometric method and high performance liquid chromatography for the analysis of flunarizine and its application for the dissolution test," Journal of Pharmaceutical and Biomedical Analysis, vol. 41, no. 1, pp. 158-164, 2006. 


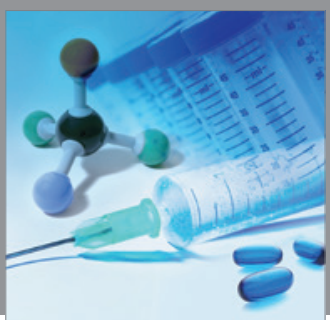

International Journal of

Medicinal Chemistry

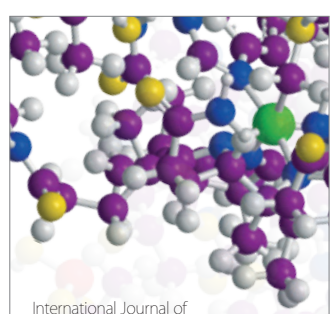

Carbohydrate Chemistry

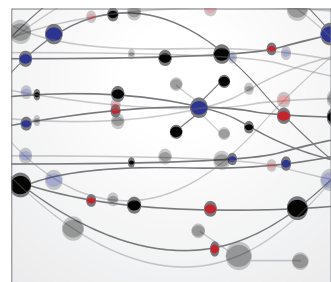

The Scientific World Journal
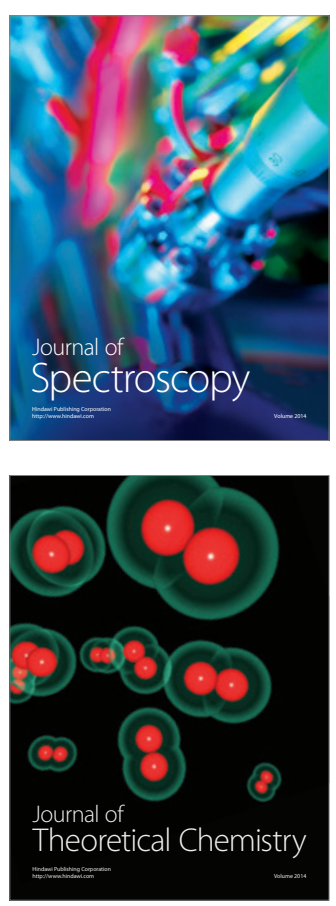
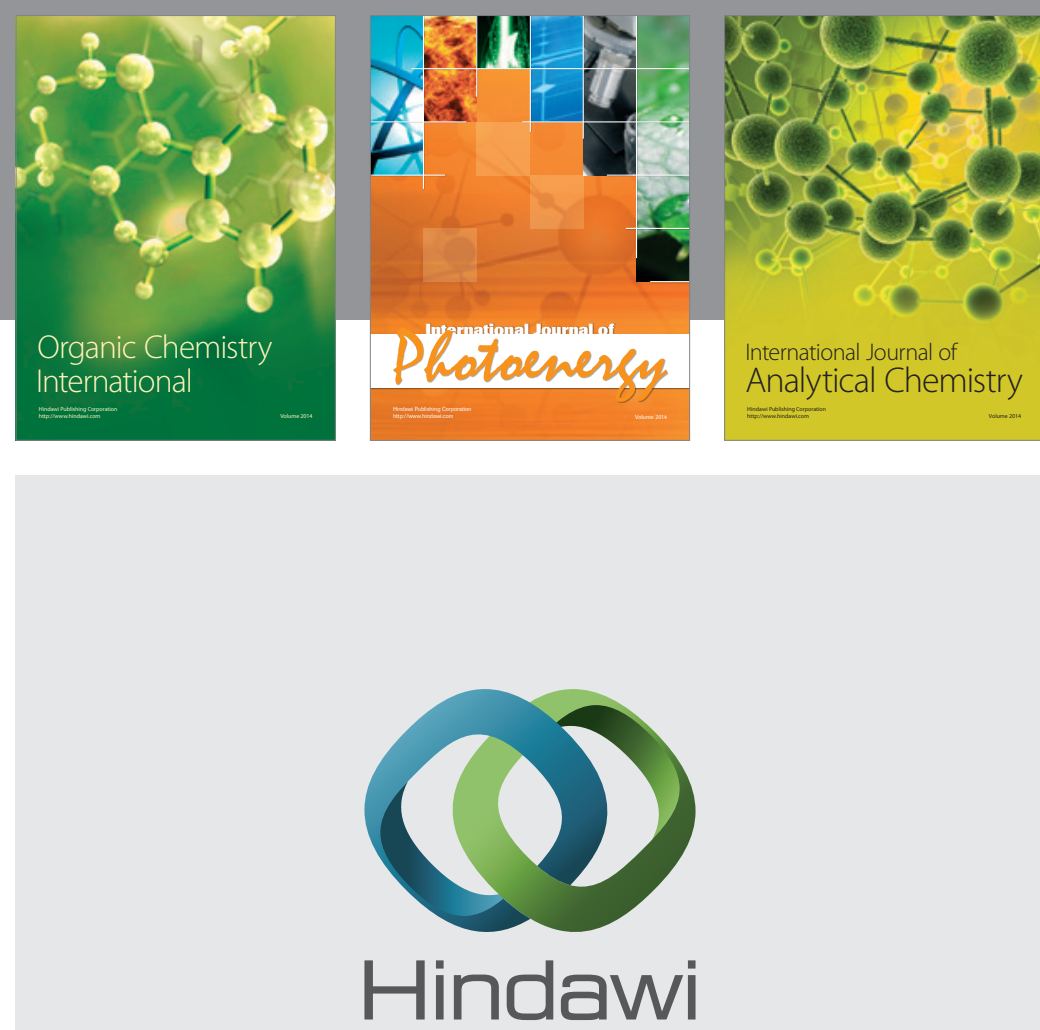

Submit your manuscripts at

http://www.hindawi.com
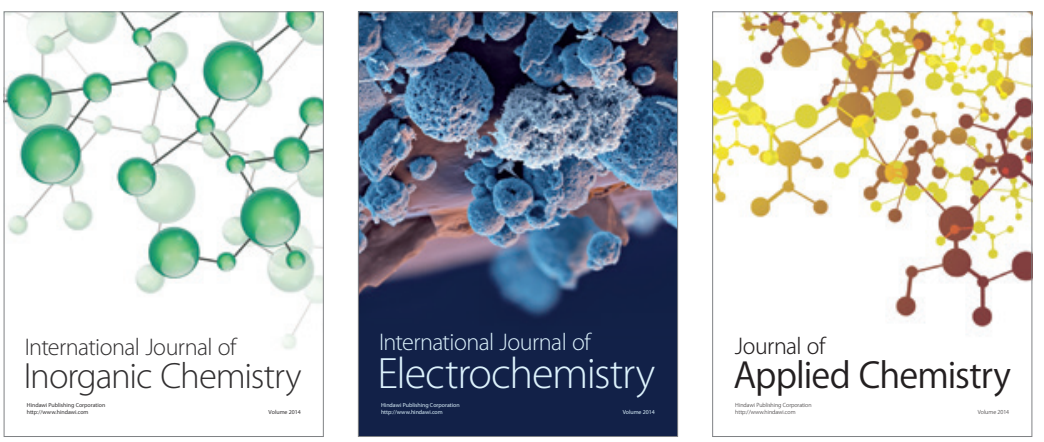

Journal of

Applied Chemistry
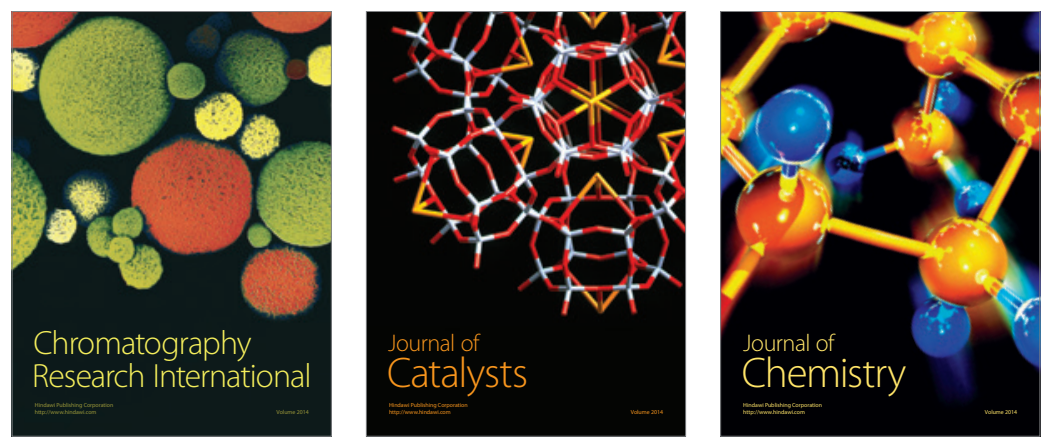
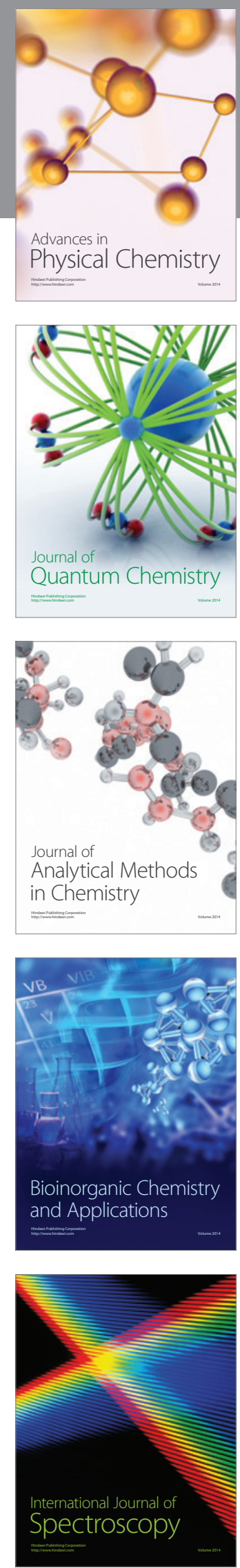